\title{
ИССЛЕДОВАНИЯ КАПИЛЛЯРНЫХ СВОЙСТВ СТЕКЛОВОЛОКНИСТОЙ БУМАГИ
}

\author{
() Е.В. Дубовой, А.С. Смолин ${ }^{1}$, И.Н. Ковернинский ${ }^{2 *}$ \\ ${ }^{1}$ Санкт-Петербургский государственный университет промышленных \\ технологий и дизайна, ул. Ивана Черных, 4, Санкт-Петербург (Россия), \\ e-mail: dubovy2004@mail.ru \\ ${ }^{2}$ НП «НПК Бумага и Картон», Москва (Россия), e-mail:kovern@list.ru
}

Проведены исследования закономерностей и установлены основные переменные факторы движения воды в капиллярно-пористых материалах из стекловолокна. Это - радиус капилляра и краевой угол смачивания. Рассмотрены основные факторы, определяющие движение воды по капиллярам и закономерности их влияния. Установлено, что эффективный радиус капилляров, краевой угол смачивания и прочность стекловолокнистой бумаги зависят от диаметра стекловолокна, вида и количества связующего, режимов формования. Выполнены расчеты зависимости высоты подъема воды в капиллярах от среднего радиуса и гидрофильности для четырех значений радиусов капилляра и краевого угла смачивания.

Ключевые слова: стеклянное волокно, стекловолокнистая бумага, пористость, капиллярность, смачивание, гидрофильность, гидрофобность, поверхностное натяжение, прямое испарительное охлаждение, связующее, влагоемкость, механическая прочность.

\section{Введение}

Одним из перспективных микропористых материалов (МПМ) для картриджей аппаратов охлаждения воздуха прямым испарением воды является бумага из стеклянного волокна $[1,2]$. Основные требования к бумаге - это высокая пористость и требуемая механическая прочность, при водо-, хемо- и биостойкости. Рабочий процесс испарения воды происходит естественно и непрерывно с плоскостей микропористого материала, за счет подвода воды из резервуара по капиллярам стекловолокнистой бумаги [3, 4]. Динамику и массу подвода воды обуславливают важнейшие явления, протекающие при контакте фаз - стекла (поверхности капилляров, образуемых стекловолокном), воды и воздуха - это смачивание, поверхностное натяжение и капиллярность [5,6]. Характеризуются они силами межфазного взаимодействия, отличающимися природой, величиной и имеющими многофакторную зависимость. Анализ действующих сил и существующих теоретических зависимостей позволяет научно обосновать выбор стекловолокна и факторов технологии формования бумаги для создания микропористой структуры с требуемыми свойствами.

Цель исследования - нахождение закономерностей смачивания, поверхностного натяжения и капиллярности при межфазном контакте стеклянного волокна, воды и воздуха в капиллярах, установление границ и величин переменных факторов.

\section{Результаты и их обсуждение}

Известно, что приведение в контакт твердого тела с водой всегда сопровождается взаимодействием,

Дубовой Евгений Владимирович - аспирант, е-таil: dubovoy.evgeniy@gmail.com

Смолин Александр Семенович - профессор, доктор технических наук, e-mail: smolin@gturp.spb.ru Ковернинский Иван Николаевич - профессор, доктор технических наук, e-mail: kovern@list.ru или, иначе, смачиванием соприкасающихся поверхностей разных фаз. Оно определяется химическим составом, морфологическими особенностями и свойствами поверхностей фаз. Различают смачивание контактное (гидрофильное) и смачи-

\footnotetext{
*Автор, с которым следуует вести переписку.
} 
вание иммерсионное (гидрофобное), определяемое соотношением сил связи молекул воды в макрообъеме воды (силы когезии) и сил связи молекул поверхности воды с поверхностью стекла (силы адгезии) [7]. Смачивание контактное определяется силами адгезии - физическими, физико-химическими, химическими и электростатическими, превалирующими над силами когезии. Этот вид смачивания характерен для гидрофильных поверхностей, включая стекло. Иммерсионное смачивание (не смачивание, а обволакивание водой гидрофобных групп, участков и поверхности в целом) обусловливается действием сил когезии, превышающих силы адгезии. Такой процесс наблюдается на гидрофобных поверхностях [8].

На твердой поверхности стекла превалируют гидрофильные силоксановые группы (рис. 1а). Они гигроскопичны, гидролизуются водой с образованием гидроксильных групп (рис. 1б). Гидроксильные группы вступают в водородные связи по типу (рис. 1в), без присоединения воды и с присоединением воды (рис. 1г). Рисунок 1 иллюстрирует смачивание стекла - повышение гидрофильности (гидрофилизацию) поверхности, за счет образования ОН групп и присоединение молекул воды (гидратацию) поверхности стекла при контакте с водой. Процесс смачивания протекает в тонкой прослойке воды у поверхности стекла - микропленке воды и проявляется изменением физических свойств воды на расстояниях до 1 мкм (1000 нм).

Свободная вода также ограничивается поверхностью. Под ней понимают трехмерные переходные слои, толщиной в несколько молекул воды на границе контактирующих фаз, называемых микропленки [9]. Толщина микропленки составляет 0,5-1,0 нм, что равно диаметрам 2-3 молекул воды (d $\mathrm{H}_{2} \mathrm{O}=0,29$ нм). Молекулы воды сильно поляризованы. Каждая молекула представляется миниатюрным диполем с высоким дипольным моментом - 1,87 Д (Дебай). За счет сил Ван-дер-Ваальса и водородных связей между атомами водорода и кислорода соседних молекул воды, часть жидкой воды объемно структурируется в кластеры (примерно 40\%), а часть остается деструктурированной - в виде отдельных молекул, которые еще называются «кванты» (примерно 60\%). Такое строение воды проявляется ее специфическим межфазным взаимодействием с дисперсной фазой (стекловолокном и связующим) в волокнистой суспензии при отливе бумаги. Воздействие диполей воды практически в 80 раз ослабляет межатомные и межмолекулярные силы на поверхности контактирующих с водой фаз.

Смачивание определяет явления поверхностного натяжения и капиллярности. Для рассмотрения явлений и обуславливаемых ими сил, а также установления управляющих факторов подъемом воды по капиллярам, обратимся к рисунку 2. На нем представлена схема действующих сил, обеспечивающих динамику перемещения воды в капилляре элементарной микропористой пластины (бумаги) аппарата прямого испарительного охлаждения воздуха.

Анализ действующих сил проведем, рассматривая рисунок 2 как два смачиваемых водой ограниченно открытых цилиндрических сосуда - резервуар с водой «А» и стеклянный капилляр «К», опущенный в воду, при условии, что радиус резервуара много больше радиуса капилляра «R». Вода в резервуаре и капилляре находится под атмосферным давлением «Ра».

Различная сила смачивания контактирующих поверхностей всегда сопровождается возникновением межфазных поверхностных сил - поверхностного натяжения, обозначаемого б. На границе «вода-воздух»

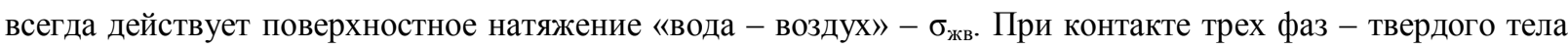
(сосуда), воды и воздуха возникают и действуют еще силы поверхностного натяжения на границах «твер-

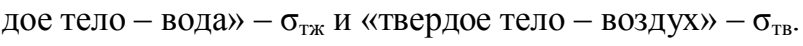

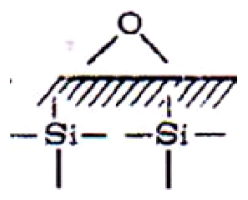

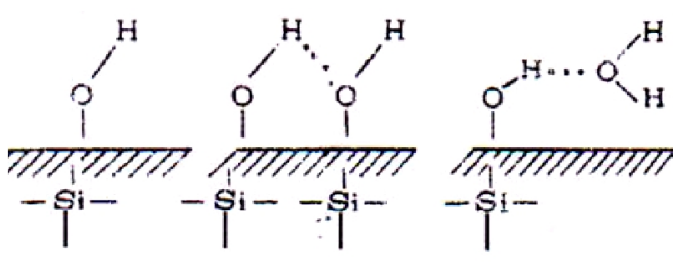

6

B

Рис. 1. Схема гидрофильности поверхности стекла: $a$ - гидрофильные силоксановые группы; $\sigma$ - гидроксильные группы открытые; 6 - группы гидроксильные закрытые; г - водородные связи с водой 
Рис. 2. Схема сил подъема воды в капилляре на границе контакта стекло, вода, воздух: А - резервуар воды; К - капилляр; Ра - давление атмосферное; $\mathrm{P}_{\text {к }}$ - капиллярное давление; $\mathrm{P}_{\text {н }}$ вес столба воды в капилляре; $r$ - радиус мениска воды в капилляре; $\mathrm{R}$ - радиус капилляра; H - высота периметра контакта граница фаз; $\mathrm{h}$ - высота подъема воды в капилляре; $\sigma_{\text {жв }}, \sigma_{\text {тв}, ~} \sigma_{\text {тж }}-$ поверхностное натяжение на границе «вода-воздух», стекло-воздух», «стекловода»; $\theta$ - краевой угол смачивания

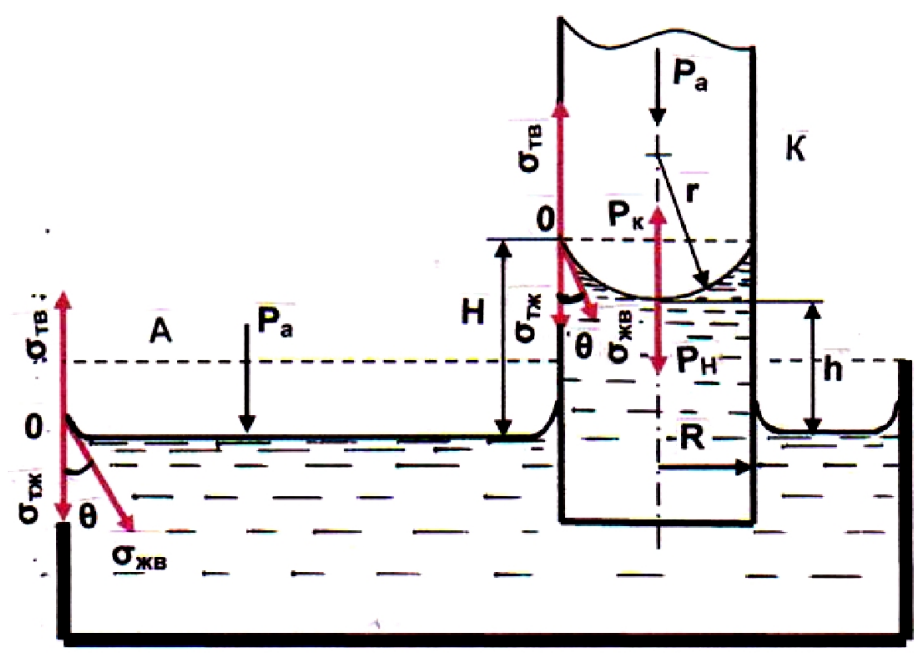

Форма поверхности воды на границе контактирующих сред в стационарном режиме определяется

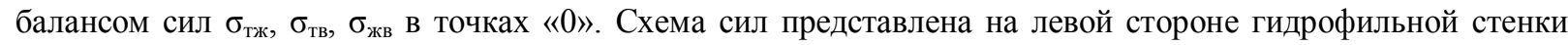
резервуара «А» и стеклянного капилляра «К». Точка «0» расположена на периметре контакта воды с сосудом, называемом линией трехфазного контакта (ЛТК), или периметром смачивания $-\mathrm{L}_{\mathrm{c}}$. B каждой точке $\mathrm{L}_{\mathrm{c}}$

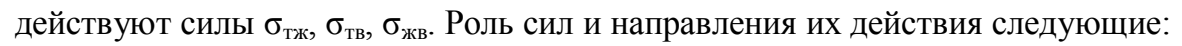

- $\quad \sigma_{\text {тж }}$ - параллельно поверхности раздела фаз «сосуд - вода» и вглубь, стремится сократить площадь контакта воды с сосудом - препятствует гидрофильному смачиванию (улучшает гидрофобное смачивание);

- $\quad \sigma_{\text {тв }}$ - параллельно поверхности раздела фаз «сосуд - воздух» вверх, стремится увеличить площадь контакта воды с сосудом - улучшает гидрофильное смачивание (снижает гидрофобное смачивание);

- $\sigma_{\text {жв }}$ - по касательной к поверхности раздела «вода-воздух», под углом $\theta$, стремится усилить или ослабить гидрофильное смачивание.

Угол $\theta$ называется «краевой угол смачивания» и является качественной и количественной характеристикой силы смачивания, или, иначе, мерой гидрофильности или гидрофобности поверхности (характеристикой гидрофильно-гидрофобного состояния поверхности). При стационарном режиме $\theta$ определяется из закона Юнга [6, 7], отражающего баланс сил на линии $\mathrm{L}_{\mathrm{c}}$ :

$$
\sigma_{\mathrm{TB}}=\sigma_{\text {Тж}}+\sigma_{\text {жВ }} \cos \theta
$$

Откуда получаем значение $\cos \theta$ :

$$
\cos \theta=\left(\sigma_{\text {тв }}-\sigma_{\text {тж}}\right) / \sigma_{\text {жв }}
$$

Краевой угол не зависит от формы сосуда и силы тяжести. Его величина определяется химическим составом, морфологией, силами когезии, адгезии, электрохимическими эффектами контактирующих фаз, рельефом и чистотой поверхности твердой фазы.

Анализ уравнения 2 позволяет оценить влияние соотношения сил на гидрофильно-гидрофобное состояние поверхности по величине $\theta$. Возможны варианты:

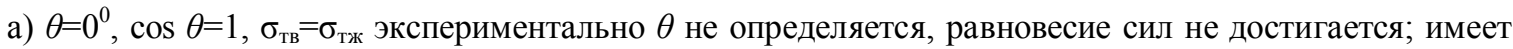
место абсолютное гидрофильное смачивание поверхности, вода по ней растекается;

б) $90^{0}>\theta>0^{0}, 0<\cos \theta<1, \sigma_{\text {тв }}>\sigma_{\text {тж }}$ поверхность гидрофильная и смачивается водой ограниченно;

в) $\theta=90^{\circ}, \cos \theta=0$; соответствует пределу гидрофильного смачивания;

г) $\theta>90^{\circ}, \cos \theta<0 ; \sigma_{\text {тв }}<\sigma_{\text {тж }}$ поверхность гидрофобная и не смачивается водой.

Капиллярность как свойство воды искривлять поверхность на границе раздела фаз [6] имеет первостепенное значение для движения воды в капиллярно-пористом теле. Механизм данного явления и действующие силы показаны на рисунке 2. На гидрофильной поверхности сосуда «А» (смачивание гидрофильное), адгезия воды к стенке больше сил когезии воды в макрообъеме сосуда и вода под действием силы $\sigma_{\text {тв }}$ 
поднимается («ползет») по сосуду вверх. Поверхность воды искривляется только у стенки с образованием вогнутого мениска с определенным средним радиусом кривизны много меньшим радиуса сосуда. Подъем воды ограничивается силой ее веса.

Если наоборот, то вода опускается, также искривляя поверхность у стенки с образованием выпуклого мениска на ограниченной поверхности.

Сближение стенок сосуда «А» до определенного максимального среднего радиуса приводит к тому,

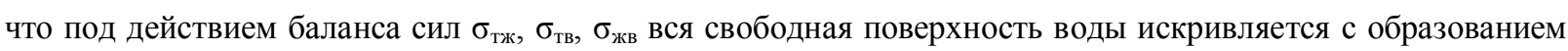
вогнутого сферического мениска. Такое поведение воды имеет место только при средних радиусах кривизны менисков сопоставимых с диаметрами капилляров, которые имеют пределы $0,5-15$ мкм $\left(0,5-15 \cdot 10^{3}\right.$ нм). Во всех случаях образование разделяющей воду и воздух пленки - в виде мениска, вызывает разницу давлений под и над мениском, представляющего собой дополнительную силу, называемую капиллярныли дав-

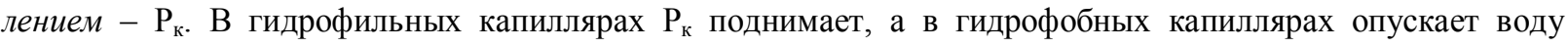
на определенную высоту h.

Величина $\mathrm{P}_{\mathrm{\kappa}}$ определяется законом Лапласа [6]:

$$
\mathrm{P}_{\mathrm{K}}=2 \sigma_{\text {жB }} / \mathrm{r}
$$

Выразим радиус кривизны мениска $\mathrm{r}$ через радиус капилляра $\mathrm{R}, \mathrm{r}=\mathrm{R} / \cos \theta$, тогда уравнение 3 примет вид

$$
\mathrm{P}_{\mathrm{K}}=2 \sigma_{\text {жВ }} \cos \theta / \mathrm{R}
$$

Из закона следует, что $P_{\text {к }}$ растет с повышением $\sigma_{\text {жв }}$ с смачивания (уменьшение $\theta$ ), и уменьшением среднего радиуса капилляра.

Используя рассмотренные закономерности, определим высоту подъема воды $\mathrm{h}$ в капилляре «К».

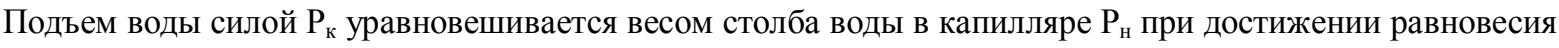

$$
\mathrm{P}_{\mathrm{K}}=\mathrm{P}_{\mathrm{H}}
$$

Капиллярное давление определяется силой поверхностного натяжения $\sigma_{ж в}$, действующей по периметру смачивания $\mathrm{L}_{\mathrm{c}}=2 \pi \mathrm{R}$, тогда $\mathrm{P}_{\mathrm{k}}=2 \sigma_{\text {жв }} \cos \theta \cdot \pi \mathrm{R}$. Уравновешивается оно весом столба воды высотой $\mathrm{h}$, который равен $\mathrm{P}_{\mathrm{H}}=\mathrm{mg}=\rho \mathrm{Vg}=\rho g \pi \mathrm{R}^{2} \mathrm{~h}$. Приравнивая обе силы $2 \sigma_{\text {жв }} \cos \theta \cdot \pi \mathrm{R}=\rho g \pi \mathrm{R}^{2} \mathrm{~h}$ и решая относительно h, получим закон Жюрена [6, 7]:

$$
\mathrm{h}=2 \sigma_{\text {жв }} \cos \theta / \rho \mathrm{gR}
$$

Для воды $\sigma_{ж в}, \rho$ и $\mathrm{g}$ - постоянные, равные, соответственно, $0,073 \mathrm{H} / \mathrm{M}, 1000$ кг $/ \mathrm{M}^{3}, 9,8 \mathrm{~m} / \mathrm{c}^{2}$ и можно ввести постоянную $\mathrm{N}=2 \cdot 0,073 / 1000 \cdot 9,8=1,5 \cdot 10^{-5} \mathrm{~m}^{2}$. Тогда уравнение 6 принимает вид

$$
\mathrm{h}=\mathrm{N} \cdot \cos \theta / \mathrm{R}=1,5 \cdot 10^{-5} \cdot \cos \theta / \mathrm{R}
$$

Согласно уравнению 7, высота подъема воды в капилляре прямо пропорциональна гидрофильному смачиванию поверхности капилляров водой и обратно пропорциональна среднему радиусу капилляра. Иными словами, чем гидрофильнее поверхность капилляров и меньше их радиус, тем на большую высоту поднимается в капиллярах вода.

Используя уравнение 7 , для воды можно определить максимальный $\mathrm{R}_{\max }$, меньше которого начинается подъем воды в капиллярах. При $\mathrm{R}_{\max }, \mathrm{h}=0, \mathrm{a} \cos \theta=1$, можно записать $1,5 \cdot 10^{-5} \cdot \cos \theta / \mathrm{R}=0$ и $\mathrm{R}_{\max }=1,5 \cdot 10^{-5} \cdot \cos \theta$ $=1,5 \cdot 10^{-5} \mathrm{M}=0,015 \mathrm{Mм}=15$ мкм.

Также имеется минимальный предел $\mathrm{R}_{\min }$, меньше которого исключается возможность подъема воды - мениск невозможен и $\mathrm{P}_{\mathrm{k}}$ отсутствует. Это состояние наступает при сопоставимости $\mathrm{R}_{\min }$, и диаметра молекул воды $-\mathrm{d}_{\mathrm{B}}\left(\mathrm{d}_{\mathrm{B}}=0,29\right.$ нм $=2,9 \cdot 10^{-4}$ мкм$)$.

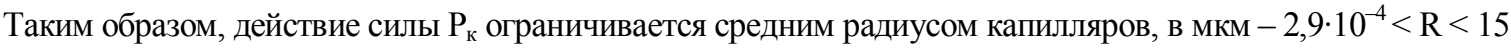
(в нм $-0,29<\mathrm{R}<15000$ ). Укажем, что стекловолокнистая бумага характеризуется поликапиллярностью 
со средним радиусом капилляров в указанных границах. Учитывая, что R является важнейшим фактором $\mathrm{h}$ и пористости, то рассмотрим основные закономерности пористости стекловолокнистой бумаги.

Стекловолокнистая бумага представляет собой физическое тело с большим объемом пустот - капилляров и пор. Она относится к жестким с ненабухающей структурой неоднороднопористым материалам. Для них характерна случайная ориентация, форма, размеры, взаимное расположение и взаимосвязь пор [10, 11]. Пористые тела классифицируют по преимущественному размеру пор на микропористые (поры до 2 нм), мезопористые (от 2 до 50 нм) и макропористые (свыше 50 нм). Объем пустот характеризуют показателем «пористость» - П, который показывает долю объема пустот (капилляров и пор) в единице общего объема бумаги.

При сравнении объема пустот - $\mathrm{V}_{\text {п }}$ и объема стекловолокна $\mathrm{V}_{\text {в }}$ в бумаге, всегда $\mathrm{V}_{\text {п }}>\mathrm{V}_{\mathrm{c}}$. Объем пор определяют, исходя из плотности стекла (истинная плотность исследуемого стекловолокна) - $\rho_{c}$ и плотностью бумаги $-\rho_{\tilde{\sigma}}$. Они связаны уравнением

$$
\mathrm{V}_{\mathrm{\Pi}}=\left(1-\rho_{\sigma} / \rho_{\mathrm{c}}\right) \cdot 100
$$

Минимальную плотность, например, имеет стекло кварцевое - 2200 кг/м³. Плотность стекловолокнистой бумаги варьируется в широких переделах. Выберем, например, бумагу из композиции стекловолокна: $25 \%$ - 0,1 мкм; 25\% - 0,25 мкм; 25\% - 0,4 мкм; 25\% - 0,6 мкм, полученную с низким расходом связующего $5 \% \mathrm{Al}_{2} \mathrm{O}_{3}$ и массой $1 \mathrm{~m}^{2} 200$ г, толщиной 0,8 мм, тогда $\rho_{\text {б }}=0,2 / 0,8 \cdot 10^{-3}=250$ кг $/ \mathrm{M}^{3}$. Подставляя данные в уравнение 8 , получим объем пор

$\mathrm{V}_{\text {п }}=(1-250 / 2200) \cdot 100=(1-0,114) \cdot 100=88,6 \%, \mathrm{~V}_{\mathrm{c}}=11,4 \%$.

$\Pi=\mathrm{V}_{\text {пI }} / \mathrm{V}_{\mathrm{c}}=7,77$. Объем пустот в бумаге превышает объем волокна в 7,77 раза. Полученная величина пористости характеризует бумагу из стекловолокна как высокопористый материал. Учитывая, что воздух в объеме пор вытесняется водой, бумагу можно отнести к высоковлагоемкому материалу.

Воспользуемся законом Жюрена и рассчитаем h подъема воды в пределах установленных значений главных факторов $-\cos \theta$ и R. Это: $60^{0}>\theta>5^{0}(0,5<\cos \theta<0,996) u 0,29<\mathrm{R}<15000$ нм. Данные приведены в таблице.

Анализ данных позволяет сравнить эффективность действия факторов $\cos \theta$ и $\mathrm{R}$ на высоту подъема воды в стеклянных капиллярах. В пределах изменения $\cos \theta 0,996-0,5$, при неизменном $\mathrm{R}, \mathrm{h}$ изменяется в 2 раза (вода поднимается или опускается). Изменение R в пределах 10-10000 нм, при неизменном соs $\theta$, например, 0,707, изменяет $\mathrm{h}$ в пределах 1,061-1061 м (вода поднимается или опускается). Изменение $\mathrm{R}$ в 10 раз приводит к изменению $\mathrm{h}$ также в 10 раз.

Таким образом, $\cos \theta$ и $\mathrm{R}$ раздельно и в сочетании являются очень эффективными влияющими факторами на динамику воды в капиллярах микропористых материалов, к которым принадлежит бумага из стекловолокна.

Однако данные получены для идеальных стеклянных капилляров. Очевидно, что общие закономерности будут соблюдаться и для неоднороднопоритых материалов, к которым принадлежит стекловолокнистая бумага. Можно определенно говорить, что в реальной бумаге одновременно имеется весь спектр пор в пределах 0,29< R $<15000$ нм, на динамику подъема воды они будут влиять согласованно как некий эффективный капилляр с $\mathrm{R}_{э ф}$.

Исследование зависимости высоты подъема воды в капиллярах от среднего радиуса и гидрофильности для 4 значений $\mathrm{R}$ и $\cos \theta$

\begin{tabular}{c|c|c|c|c|c}
\hline \multirow{2}{*}{ Виды пор } & \multicolumn{2}{|c|}{$\mathrm{R}$} & \multirow{2}{*}{$\mathrm{N}, \mathrm{m}^{2}$} & $\cos \theta$ & $\mathrm{h}, \mathrm{m}$ \\
\cline { 1 - 3 } & $\mathrm{HM}$ & $\mathrm{M}$ & & & \\
\hline Макропоры & 10000 & $10^{-5}$ & $1,5 \cdot 10^{-5}$ & $0,996 / 0,906 / 0,707 / 0,5$ & $1,494 / 1,359 / 1,061 / 0,75$ \\
& 1000 & $10^{-6}$ & & $0,996 / 0,906 / 0,707 / 0,5$ & $14,494 / 13,59 / 10,61 / 7,5$ \\
& 100 & $10^{-7}$ & & $0,996 / 0,906 / 0,707 / 0,5$ & $144,94 / 135,9 / 106,1 / 75$ \\
& 10 & $10^{-8}$ & & $0,996 / 0,906 / 0,707 / 0,5$ & $1449,4 / 1359,0 / 1061,0 / 750$ \\
\cline { 2 - 3 } & 1 & $10^{-9}$ & & $0,996 / 0,906 / 0,707 / 0,5$ & $14494 / 13590 / 10610 / 7500$ \\
\hline
\end{tabular}

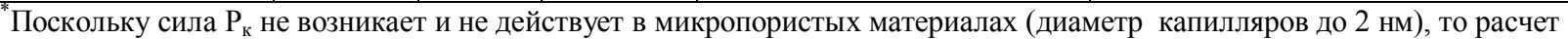
приведен для сравнения. 
Наряду с высотой подъема воды большое значение имеют факторы - скорость подъема воды, обо-

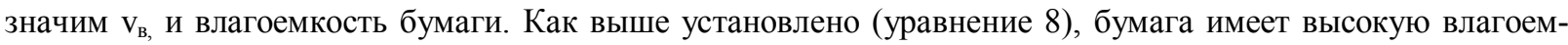
кость, равную $\mathrm{V}_{\text {п. }}$ Скорость подъема воды можно выразить уравнением

$$
\mathrm{v}_{\mathrm{B}}=\mathrm{h} / \tau \text {. }
$$

Подставляя значение $\mathrm{h}$ по уравнению Жюрена, с учетом $\mathrm{R}=\mathrm{R}_{э ф}$, получим

$$
\mathrm{V}_{\mathrm{B}}=1,5 \cdot 10^{-5} \cdot \cos \theta / \tau \mathrm{R}_{\ni \phi}, \mathrm{M} / \mathrm{c} .
$$

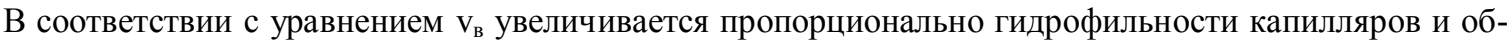
ратно пропорционально $\tau$ и $\mathrm{R}_{э ф}$.

Следуя принципу работы охладителей воздуха прямым испарением воды, масса поднимаемой по капиллярам воды $\mathrm{m}_{\text {в }}$ должна восполнять массу испаряемой воды $\mathrm{m}_{\text {и. }}$ В стационарном режиме $\mathrm{m}_{\mathrm{s}}=\mathrm{m}_{\text {и. }}$.

Совместное действие факторов $\mathrm{R}_{\text {эф }}, \cos \theta, \mathrm{m}_{\text {в }}$ и $\mathrm{v}_{\text {в }}$ можно оценивать показателем «впитываемость капиллярная» [12]. Для стекловолокнистой бумаги показатель информативный и легкоопределяемый.

\section{Bbbodbl}

1. Теоретически исследованы закономерности и основные переменные факторы динамики движения воды в капиллярно-пористых материалах из стекловолокна; это факторы $\mathrm{R}$ и $\cos \theta$, с пределами, соответственно, 10-10000 нм и 0,996-0,5.

2. Для оценки совместного влияния факторов $\mathrm{R}_{э ф}, \cos \theta, \mathrm{m}_{\mathrm{B}}$ и $\mathrm{v}_{\mathrm{B}}$ на динамику движения воды в стекловолокнистой бумаге следует использовать показатель «впитываемость капиллярная».

3. Закономерности влияния факторов $\mathrm{R}_{\text {эф, }} \cos \theta, \mathrm{m}_{\mathrm{B}}$ и $\mathrm{v}_{\mathrm{B}}$ целесообразно применить для расчета физических размеров пластин стекловолокнистой бумаги для испарения воды, конструкции картриджей и аппарата прямого испарительного охлаждения воздуха.

4. Учитывая, что $\mathrm{R}_{\text {эф }}, \cos \theta$ и прочность стекловолокнистой бумаги зависят от диаметра стекловолокна, вида и количества связующего, режимов формования, исследование зависимостей является актуальной задачей продолжения научной работы.

\section{Заключение}

В результате теоретического исследования рассмотрены основные явления, протекающие при контакте стеклянного волокна и воды, установлены закономерности протекания данных явлений в капиллярно-пористой структуре стекловолокнистой бумаги. Определены основные факторы, влияющие на движение воды в стекловолокнистой бумаге и их пределы. Проведены оценочные расчеты высоты подъема воды в стекловолокнистой бумаге. Полученные результаты показывают, что стекловолокнистая бумага может быть использована в качестве микропористого материала для аппаратов охлаждения воздуха методом прямого испарения воды.

\section{Сиисок литературь}

1. Свиридов Е.Б., Сысоева Н.В., Дубовый В.К., Безлаковский А.И. Природный потенциал охлаждения. Энергосберегающая экологически безопасная технология охлаждения воздуха широкомасштабного применения. 2-е изд., доп. СПб., 2015. 256 с.

2. Дубовый В.К. Бумагоподобные композиционные материалы на основе минеральных волокон: дис. ... д-ра техн. наук. СПб, 2006.

3. Сиркар А. Знакомство со стекловолокном и технологией его производства с использованием процесса создания нетканых материалов // TAPPI JOURNAL. 1993. Vol. 76, №4. C. 167-175.

4. Дубовый В.К. Стеклянные волокна. Свойства и применение. СПб., 2003. 130 с.

5. Адамсон А. Физическая химия поверхностей. М., 1979. 568 с.

6. Сумм Б.Д., Горюнов Ю.В. Физико-химические основы смачивания и растекания. М., 1976. 232 с.

7. Воюцкий С.С. Курс коллоидной химии. М., 1975. 155 с.

8. Пчелин В.А. Гидрофобное взаимодействие в дисперсных системах. М., 1976. 64 с.

9. Ивчатов А.Л., Малов В.И. Химия воды и микробиология. М., 2006. 218 с.

10. Грег С., Синг К. Адсорбция, удельная поверхность, пористость. Пер. с англ., 2 изд. М., 1970. 408 с.

11. Хейфец Л.И., Неймарк А.В. Многофазные процессы в пористых средах. М., 1982. 320 с.

12. Стид Дж.В., Этвуд Дж.Л. Супрамолекулярная химия: в 2 т. М., 2007. Т. 1. 479 с. 
Dubovoy E.V. ${ }^{I}$, Smolin A.S. ${ }^{l}$, Koverninckiy I.N. ${ }^{2 *}$ STUDY OF CAPILLARY PROPERTIES OF GLASS-FIBER PAPER

${ }^{I}$ Saint Petersburg State University of Industrial Technologies and Design, Ivana Chernykh str., 4, St. Petersburg (Russia),e-mail: dubovoy.evgeniy@gmail.com

${ }^{2}$ Scientific enterprise "Paper and Cardboard", Ozerkovskaya str., 24, Moscow (Russia), e-mail: kovern@list.ru

The studies of regularities have been carried out and the main variable factors of water movement in capillary-porous fiberglass materials have been established. This is the radius of the capillary and the contact angle of wetting. The main factors that determine the movement of water through the capillaries and the laws of their influence were determined. It is established that the effective radius of the capillaries, the contact angle and the strength of the glass-fiber paper depend on the diameter of the glass fiber, the type and amount of binder, the molding regimes. Calculations of the dependence of the height of water rise in the capillaries on the mean radius and hydrophilicity for 4-th values of the capillary radius and the wetting contact angle are performed.

Keywords: Glass fiber, fiberglass paper, porosity, capillarity, wetting, hydrophilicity, hydrophobicity, surface tension, direct evaporative cooling, binder, moisture capacity, mechanical strength.

\section{References}

1. Sviridov E.B., Sysoeva N.V., Dubovyi V.K., Bezlakovskii A.I. Prirodnyi potentsial okhlazhdeniia. Energosberegaiushchaia ekologicheski bezopasnaia tekhnologiia okhlazhdeniia vozdukha shirokomasshtabnogo primeneniia. [Natural cooling potential. Energy-saving environmentally friendly air cooling technology for largescale application]. St. Petersburg, 2015, 256 p. (in Russ.).

2. Dubovyi V.K. Bumagopodobnye kompozitsionnye materialy na osnove mineral'nykh volokon : dis. ... d-ra tekhn. nauk. [Paper-like composite materials on the basis of mineral fibers: the dissertation of the doctor of technical sciences]. St. Petersburg, 2006. (in Russ.).

3. Sirkar A. Tappi Journal, 1993, vol. 76, no. 4, pp. 167-175.

4. Dubovyi V.K. Stekliannye volokna. Svoistva i primenenie. [Glass fibers. Properties and application]. St. Petersburg, 2003, 130 p. (in Russ.).

5. Adamson A. Fizicheskaia khimiia poverkhnostei. [Physical chemistry of surfaces]. Moscow, 1979, 568 p. (in Russ.).

6. Summ B.D., Goriunov Iu.V. Fiziko-khimicheskie osnovy smachivaniia i rastekaniia. [Physico-chemical basis of wetting and spreading]. Moscow, 1976, 232 p. (in Russ.).

7. Voiutskii S.S. Kurs kolloidnoi khimii. [Course of colloid chemistry]. Moscow, 1975, 155 p. (in Russ.).

8. Pchelin V.A. Gidrofobnoe vzaimodeistvie $v$ dispersnykh sistemakh. [Hydrophobic interaction in disperse systems]. Moscow, 1976, 64 p. (in Russ.).

9. Ivchatov A.L., Malov V.I. Khimiia vody i mikrobiologiia. [Water chemistry and microbiology]. Moscow, 2006, 218 p. (in Russ.).

10. Greg S., Sing K. Adsorbtsiia, udel'naia poverkhnost', poristost'. [Adsorption, specific surface, porosity]. Moscow, 1970. 408 c. (in Russ.).

11. Kheifets L.I., Neimark A.V. Mnogofaznye protsessy v poristykh sredakh. [Multiphase processes in porous media]. Moscow, 1982, 320 p. (in Russ.).

12. Stid Dzh.V., Etvud Dzh.L. Supramolekuliarnaia khimiia. [Supramolecular chemistry]. In 2 vol., Moscow, 2007, vol. 1, 479 p. (in Russ.).

Received May 21, 2017

Revised Juny 30, 2017

\footnotetext{
* Corresponding author.
} 
